\title{
Comparative analysis of maternal and fetal outcomes of pregnancies complicated and not complicated with hyperemesis gravidarum necessitating hospitalization
}

\section{Taner Günay ( $\nabla$ drtanergunay@gmail.com )}

Medeniyet Universitesi Goztepe Egitim ve Arastirma Hastanesi https://orcid.org/0000-0002-3985-0702

Meryem Hocaoğlu

Medeniyet Universitesi Goztepe Egitim ve Arastirma Hastanesi

Ergül Demirçivi Bör

Medeniyet Universitesi Goztepe Egitim ve Arastirma Hastanesi

Abdulkadir Turgut

Medeniyet Universitesi Goztepe Egitim ve Arastirma Hastanesi

\section{Research article}

Keywords: Pregnancy, hyperemesis gravidarum, hospitalization, fetal outcomes, maternal outcomes, controls

Posted Date: September 4th, 2019

DOl: https://doi.org/10.21203/rs.2.13892/v1

License: (c) (1) This work is licensed under a Creative Commons Attribution 4.0 International License.

Read Full License

Version of Record: A version of this preprint was published at Medeniyet Medical Journal on January 1st, 2020. See the published version at https://doi.org/10.5222/MMJ.2020.57767. 


\section{Abstract}

Background Hyperemesis gravidarum is considered to be one of the most common causes of hospitalization during the first half of pregnancy, and is a potentially life-threatening condition. The purpose of this study to evaluate maternal and fetal outcomes of pregnancies complicated and not complicated with hyperemesis gravidarum necessitating hospitalization.

Methods A total of 386 women with singleton deliveries between March 2015 and March 2019 were included in this retrospective single-center study. Of 386 women, 186 women who were hospitalized with hyperemesis gravidarum within the first 20 weeks of gestation comprised the hyperemetic pregnancy group, while 200 women without hyperemesis gravidarum during pregnancy served as a control group. Fisher's exact test, Pearson Chi-Square test, Fisher Freeman Halton Test (Monte Carlo) and Mann-Whitney U test were used for data analysis.

Results No significant difference was noted between the hyperemesis gravidarum and control groups in terms of maternal characteristics, gestational age (median 38.6 and 39.0 weeks, respectively), type of delivery (normal spontaneous delivery in $78.0 \%$ and $80.0 \%$, respectively), fetal gender (female: $53.2 \%$ and $48.5 \%$, respectively), birthweight (median $3250 \mathrm{~g}$ and $3275 \mathrm{~g}$, respectively) and 5-min APGAR scores ( $\geq 7$ in $97.3 \%$ and $97.5 \%$, respectively). Adverse pregnancy outcomes were also similar between groups including preterm birth (8.1\% and $11.0 \%$, respectively), SGA (5.9\% and $9.5 \%$, respectively), hypertensive disorder (5.4\% and $7.5 \%$, respectively), placental abruption ( $1.1 \%$ and $0.5 \%$, respectively), stillbirth $(0.0 \%$ and $0.5 \%$, respectively) and GDM (3.8\% and $2.5 \%$, respectively). Weight loss during pregnancy was evident in $94.0 \%$ of women in the hyperemesis gravidarum group, while none of women in the control group had weight loss during pregnancy $(p<0.001)$.

Conclusion The findings of this study revealed that pregnancies complicated with hyperemesis gravidarum were not associated with increased risk for adverse fetal and maternal outcomes compared with the healthy control pregnancies.

\section{Background}

Hyperemesis gravidarum, unlike the nausea and vomiting experienced by many women in early pregnancy, is a potentially life-threatening condition with a prevalence that ranges from 0.3 to $3 \%$ of pregnancies, depending on the diagnostic criteria and ethnic variation of study populations $[1,2]$.

Hyperemesis gravidarum is considered to be one of the most common causes of hospitalization during the first half of pregnancy, and is a disease for which the diagnosis is based on clinical judgment given the lack of well-defined diagnostic criteria $[2,3]$.

Notably, the adverse impact of hyperemesis gravidarum on pregnancy outcomes, particularly for the offspring, is still debated in literature with conflicting results regarding the associated risk for low 
birthweight, preterm birth, small-for-gestational-age (SGA), stillbirth and abnormalities of placental conditions [2-8].

Therefore, there is a need for studies addressing the potential effect of hyperemesis gravidarum on pregnancy outcomes via uniform diagnostic criteria and valid data on exposure and outcome measures as well as potential confounders [2,3].

\section{Methods}

This retrospective cohort study of singleton deliveries was therefore designed to comparatively evaluate the maternal and fetal outcomes of pregnancies complicated or not with hyperemesis gravidarum necessitating hospitalization.

\section{Study design and population}

A total of 386 women (median age 26 years, ranged 17 to 39 years) with singleton deliveries between March 2015 and March 2019 were included in this retrospective single-center study. Of 386 women, 186 women (mean $\pm S D$ age: $30.7 \pm 5.9$ years) who were hospitalized with hyperemesis gravidarum within the first 20 weeks of gestation comprised the hypermetic pregnancy group, while 200 women without hyperemesis gravidarum during pregnancy served as a control group. Hyperemesis gravidarum was defined as long-lasting nausea and vomiting requiring antepartum hospitalizations for hyperemesis before the 20th week of gestation. All pregnant women who were hospitalized in our center within the study period due to hyperemesis gravidarum during the first 20 weeks of gestation were included in the study. Pregnant women with hyperemesis gravidarum treated on an outpatient basis, those at $>20$ weeks of gestation and those with deliveries in other hospitals were excluded from the study.

The study was conducted in full accordance with local Good Clinical Practice (GCP) guidelines and current legislation, and permission was obtained from our institutional ethics committee for the use of patient data for publication purposes.

\section{Study parameters}

Data on maternal characteristics (age, smoking status, parity, weight loss during pregnancy), delivery characteristics (gestational age, type of delivery), fetal characteristics (gender, birthweight, 5-min APGAR scores) and adverse pregnancy outcomes including preterm birth, small for gestational age (SGA), pregnancy-induced hypertensive disorder, placental abruption, stillbirth and gestational diabetes mellitus (GDM) were recorded in both the hyperemesis gravida and control groups.

\section{Definitions for adverse pregnancy outcomes}


Hypertensive disorders of pregnancy were classified according to the International Society for the study of Hypertension in Pregnancy (ISSHP) definitions [9]. Gestational hypertension was defined as systolic blood pressure of $140 \mathrm{mmHg}$ or more and/or diastolic blood pressure of $90 \mathrm{mmHg}$ or more on two occasions in a woman with no hypertension prior to 20 weeks of gestation. In women with gestational hypertension, proteinuria was defined as $1+$ dipstick in random urine samples. Pre-eclampsia was diagnosed if women with gestational hypertension had proteinuria. Chronic hypertension was defined as blood pressure exceeding 140/90 mmHg before pregnancy or before 20 weeks gestation, and only when found to be elevated on $\geq 2$ occasions. Women diagnosed with gestational hypertension or pre-eclampsia received treatment according to the standard hospital protocols.

Preterm delivery was accepted as $<37$ gestation-week deliveries. Stillbirth was defined as birth of an infant with no signs of life at or after 24 weeks of gestation. Small for Gestational Age (SGA) was defined as birth weight at a particular gestational age below the 10th percentile.

\section{Statistical analysis}

Statistical analysis was made using IBM SPSS Statistics for Windows, Version 25.0 software (IBM Corp., Armonk, NY, USA). Fisher's exact test, Pearson Chi-Square test and Fisher Freeman Halton Test (Monte Carlo) were used to analyze categorical variables, while numerical data were analyzed using the MannWhitney U test. Data were expressed as mean (standard deviation; SD), minimum-maximum, quartiles $(\mathrm{Q} 1, \mathrm{Q} 3)$ and number $(\mathrm{n})$ and percentage (\%) where appropriate. A value of $\mathrm{p}<0.05$ was considered statistically significant.

\section{Results}

\section{Maternal characteristics}

No significant difference was noted between the hyperemesis gravidarum and control groups in terms of maternal characteristics including age (median 26 years for each), rate of non-smokers $(94.6 \%$ and $95.0 \%$, respectively) and parity (57\% were nulliparous in each group) (Table 1$)$.

Weight loss during pregnancy was evident in $94.0 \%$ of women (up to $6.9 \mathrm{~kg}$ in $74.1 \%$ ) in the hyperemesis gravidarum group, while none of women in the control group had weight loss during pregnancy $(p<0.001$, Table 1).

\section{Delivery characteristics}

No significant difference was noted between the hyperemesis gravidarum and control groups in terms of delivery characteristics including gestational age (median 38.6 and 39.0 weeks, respectively) and type of delivery (Normal spontaneous delivery in $78.0 \%$ and $80.0 \%$, respectively) (Table 2 ). 


\section{Fetal characteristics}

No significant difference was noted between the hyperemesis gravidarum and control groups in terms of fetal characteristics including gender (female: $53.2 \%$ and $48.5 \%$, respectively), birthweight (median 3250 $\mathrm{g}$ and $3275 \mathrm{~g}$, respectively), 5-min APGAR scores ( $\geq 7$ in $97.3 \%$ and $97.5 \%$, respectively) (Table 2).

\section{Adverse pregnancy outcomes}

No significant difference was noted between the hyperemesis gravidarum and control groups in terms of adverse pregnancy outcomes including rates for preterm birth ( $8.1 \%$ and $11.0 \%$, respectively), SGA delivery (5.9\% and $9.5 \%$, respectively), hypertensive disorder ( $5.4 \%$ and $7.5 \%$, respectively), placental abruption ( $1.1 \%$ and $0.5 \%$, respectively), stillbirth ( $0.0 \%$ and $0.5 \%$, respectively) and GDM $(3.8 \%$ and $2.5 \%$, respectively) (Table 3$)$.

Pregnancy-induced hypertensive disorder in the hyperemesis gravidarum $(n=10)$ and control $(n=15)$ groups involved preeclampsia (in 5 and 7 cases, respectively), gestational hypertension (in 4 and 7 cases, respectively) and chronic hypertension with superimposed pre-eclampsia (1 case in each group).

\section{Discussion}

The findings of this study of a retrospective cohort of women with singleton deliveries who experienced pregnancies complicated or not with hyperemesis gravidarum revealed no significant impact of hyperemesis gravidarum on maternal and fetal outcomes in terms of fetal birthweight, 5-min APGAR scores, preterm birth, SGA, pregnancy-induced hypertensive disorder, placental abruption, stillbirth and GDM.

Similar to these findings, in a previous retrospective cohort study of fetal and maternal outcomes in pregnancies with or without hyperemesis from Turkey, no statistically significant differences were reported between pregnancies with or without hyperemesis in terms of rates of SGA birth, preterm birth, Apgar scores, fetal birth weight, gestational diabetes, pregnancy-induced hypertension, or fetal gender and type of delivery [8]. The authors of that study concluded that hyperemesis gravidarum was not associated with adverse pregnancy outcomes [8].

Likewise, in a Norwegian mother and infant cohort of 71,468 singleton pregnancies, no association of hyperemesis gravidarum was reported with low birthweight, preterm birth, delivering SGA infant and 5min Apgar scores, regardless of the maternal weight gain ( $<7$ kilos or $\geq 7$ kilos) [3].

The current study findings revealed similar risks for placental abruption and placental insufficiency disorders including gestational hypertension, pre-eclampsia and stillbirth in pregnancies complicated or not with hyperemesis gravidarum. This supports the data from a prospective cohort study of 2252 pregnant women, which indicated no association of hyperemesis gravidarum with placental insufficiency 
(gestational hypertension, pre-eclampsia, stillbirth, miscarriage), with poor neonatal outcomes (birth weight, SGA, low birth weight, Apgar score at $5 \mathrm{~min}$, gestational age at delivery) and placental outcomes (placental weight, and placental weight to birth weight ratio) [10].

However, although the current study findings support the view that that hyperemesis gravidarum requiring hospitalization was not associated with an increased risk for preterm birth, low birth weight or SGA [3,8], it should be noted that there are conflicting data in literature on fetal outcomes and placental conditions after in-utero exposure to maternal hyperemesis gravidarum [2].

In a population-based retrospective Norwegian cohort study of 156,000 singleton pregnancies, hyperemetic pregnancies were reported to be associated with an increased risk of low birth weight, SGA, preterm delivery, 5-min Apgar scores $<7$ (relative risks of 3.0, 2.8, 1.5 and 5.0, respectively) compared to pregnancies without hyperemesis, but only for women gaining less than $7 \mathrm{~kg}$ during pregnancy [4]. The authors indicated that the adverse infant outcomes associated with hyperemesis were related to and mostly limited to poor maternal weight gain [4].

In a Swedish cohort study, hyperemesis gravidarum in the first trimester was reported to be associated with an increased risk of later occurring pre-eclampsia, and preterm delivery with pre-eclampsia, in addition to placental abruption and delivering an SGA infant [11].

Findings from a Dutch historical cohort study of 1.2 million singleton births revealed an association of hyperemesis gravidarum with an increased risk for preterm delivery but not for SGA or low birth weight [12]. An American cohort study of 520,000 live births reported that hyperemesis gravidarum was associated with a higher likelihood of delivering a low birthweight and SGA infant [6].

In a meta-analysis of 13 case-control studies, 10 cohort studies and one cross-sectional study on hyperemesis gravidarum and pregnancy outcomes, it was reported that hyperemesis gravidarum was associated with a $30 \%$ increase in risk for preterm birth and SGA, and a $40 \%$ increase in risk for low birthweight [13].

In fact, low maternal gestational weight gain, regardless of maternal hyperemesis status, has been considered to be associated with an increased risk of preterm birth, low birth weight and intrauterine growth retardation $[14,15]$. This emphasizes the associations between hyperemesis gravidarum and adverse pregnancy outcomes to be related to poor maternal weight gain rather than the direct effect of hyperemesis gravidarum $[3,4,7]$, in addition to the greater risk for growth retardation and fetal anomalies in hyperemesis gravidarum cases with weight loss $>5 \%$ of the pre-pregnancy weight [7].

Given that weight loss was evident ( $<6.9 \mathrm{~kg}$ in74.1\% and $7-14.9 \mathrm{~kg}$ in $13.3 \%$ ) in $91.4 \%$ of the women with hyperemesis gravidarum in the current study cohort, the lack of association of hyperemesis gravidarum or concomitant weight loss with adverse pregnancy outcomes supports the view that with good antenatal care and management of women hospitalized with hyperemesis gravidarum, the risk of adverse pregnancy outcomes is likely to be diminished [3]. 
Nonetheless, whether or not hyperemesis gravidarum was associated with negative short-term consequences, the possibility of long-term consequences related to fetal undernutrition during first trimester has also been suggested, including an increased risk for cardiovascular disease, diabetes and schizophrenia in later life $[3,16,17]$.

Although the exact etiology of hyperemesis gravidarum remains unknown, it is considered to be a multifactorial disease [2]. The characteristics of women with hyperemetic pregnancies in the current study cohort support the consideration of hyperemesis gravidarum as a pregnancy-related complication being more commonly observed among young, non-smoker and primiparous mothers $[2,18,19]$.

While adverse pregnancy outcomes of hyperemesis gravidarum are conflicting and the current study findings revealed no association of the condition with an increased risk of fetal or maternal outcomes compared to the control pregnancies, it should be noted that hyperemesis gravidarum has been associated with a significant psychosocial burden in women together with an adverse impact on daily activities [20]. This seems notable given the reported lack of support from healthcare professionals and suboptimal management of women with hyperemesis gravidarum [20].

\section{Conclusion}

These findings of a retrospective cohort of women with singleton deliveries who experienced pregnancies complicated or not with hyperemesis gravidarum, revealed no significant impact of hyperemesis gravidarum on maternal and fetal outcomes in terms of fetal birthweight, 5-min APGAR scores, preterm birth, SGA, pregnancy-induced hypertensive disorder, placental abruption, stillbirth and GDM. Future studies addressing not only short-term consequences but also possible long-term risks of hyperemesis gravidarum on the offspring are needed alongside the consideration of the perspectives of women suffering from hyperemesis gravidarum to be able to improve the management of the condition in terms of both fetal and maternal well-being.

\section{Abbreviations}

SGA:Small for gestational age; GDM:Gestational diabetes mellitus; ISSHP: International Society for the study of Hypertension in Pregnancy

\section{Declarations}

\section{Acknowledgements}

We would like to thank the supervisor and the archive officer who helped us during data collection.

\section{Authors' contributions}


TG conceived the study. MH and EDB designed the data collection form and collected data. AT contributed to study design.TG, AT analysed the data. MH wrote the first draft of the manuscript. All authors interpreted the data and edited the manuscript. All authors reviewed and approved the final version of manuscript.

\section{Funding}

None

\section{Availability of data and materials}

The data used during the current study are available from the corresponding author on reasonable request.

\section{Ethics approval and consent to participate}

While the present study was exempt from the requirement of ethical approval in relation to its retrospective design, the permission was obtained from our institutional ethics committee for the use of patient data for publication purposes. Ethical approval was obtained from the Medeniyet University Göztepe Training and Research Hospital Ethics Committee (2018/002).

\section{Consent for publication}

Not applicable.

\section{Competing interests}

The authors declare that they have no competing interests.

\section{References}

1. Verberg MF, Gillott DJ, Al Fardan N, Grudzinskas JG (2005) Hyperemesis gravidarum, a literature review. Hum Reprod Update 11:527-539. https://doi.org/10.1093/humupd/dmi021

2. London V, Grube S, Sherer DM, Abulafia O (2017) Hyperemesis Gravidarum: A Review of Recent Literature. Pharmacology 100:161-171. https://doi.org/10.1159/000477853

3. Vikanes ÅV, Støer NC, Magnus P, Grjibovski AM (2013) Hyperemesis gravidarum and pregnancy outcomes in the Norwegian Mother and Child Cohort - a cohort study. BMC Pregnancy Childbirth 13:169. https://doi.org/10.1186/1471-2393-13-169 
4. Dodds L, Fell DB, Joseph KS, Allen VM, Butler B (2006) Outcomes of pregnancies complicated by hyperemesis gravidarum. Obstet Gynecol 107:285-292. https://doi.org/10.1097/01.AOG.0000195060.22832.cd

5. Paauw JD, Bierling S, Cook CR, Davis AT (2005) Hyperemesis gravidarum and fetal outcome. JPEN J Parenter Enteral Nutr 29:93-96. https://doi.org/10.1177/014860710502900293

6. Bailit JL (2005) Hyperemesis gravidarium: epidemiologic findings from a large cohort. Am J Obstet Gynecol 193:811-814. https://doi.org/10.1016/j.ajog.2005.02.132

7. Gross S, Librach C, Cecutti A (1989) Maternal weight loss associated with hyperemesis gravidarum: a predictor of fetal outcome. Am J Obstet Gynecol 160:906-909.

8. Kuru O, Sen S, Akbayır O, Goksedef BP, Ozsürmeli M, Attar E, Saygılı H (2012) Outcomes of pregnancies complicated by hyperemesis gravidarum. Arch Gynecol Obstet 285:1517-1521. https://doi.org/10.1007/s00404-011-2176-3

9. Brown MA, Magee LA, Kenny LC, Karumanchi SA, McCarthy FP, Saito S, Hall DR, Warren CE, Adoyi G, Ishaku S; International Society for the Study of Hypertension in Pregnancy (ISSHP) (2018) Hypertensive Disorders of Pregnancy: ISSHP Classification, Diagnosis, and Management Recommendations for International Practice. Hypertension 72:24-43. https://doi.org/10.1161/HYPERTENSIONAHA.117.10803

10. Koudijs HM, Savitri Al, Browne JL, Amelia D, Baharuddin M, Grobbee DE, Uiterwaal CS (2016) Hyperemesis gravidarum and placental dysfunction disorders. BMC Pregnancy Childbirth 16:374. https://doi.org/10.1186/s12884-016-1174-7

11. Bolin M, Åkerud H, Cnattingius S, Stephansson O, Wikström AK (2013) Hyperemesis gravidarum and risks of placental dysfunction disorders: a population-based cohort study. BJOG 120:541-547. https://doi.org/10.1111/1471-0528.1213

12. Roseboom TJ, Ravelli AC, van der Post JA, Painter RC (2011) Maternal characteristics largely explain poor pregnancy outcome after hyperemesis gravidarum. Eur J Obstet Gynecol Reprod Biol156:5659. https://doi.org/10.1016/j.ejogrb.2011.01.010

13. Veenendaal MV, van Abeelen AF, Painter RC, van der Post JA, Roseboom TJ (2011) Consequences of hyperemesis gravidarum for offspring: a systematic review and meta-analysis. BJOG 118:13021313. https://doi.org/10.1111/j.1471-0528.2011.03023.x

14. Han Z, Lutsiv O, Mulla S, Rosen A, Beyene J, McDonald SD; Knowledge Synthesis Group (2011) Low gestational weight gain and the risk of preterm birth and low birthweight: a systematic review and meta-analyses. Acta Obstet Gynecol Scand 90:93-954. https://doi.org/10.1111/j.16000412.2011.01185.x.

15. McDonald SD, Han Z, Mulla S, Beyene J; Knowledge Synthesis Group (2010) Overweight and obesity in mothers and risk of preterm birth and low birth weight infants: systematic review and metaanalyses. BMJ 341:c3428. https://doi.org/10.1136/bmj.c3428.

16. Roseboom TJ, Painter RC, van Abeelen AFM, Veenendaal MVE, de Rooij SR (2011) Hungry in the womb: what are the consequences? Lessons from the Dutch famine. Maturitas 70:141-145. 
https://doi.org/10.1016/j.maturitas.2011.06.017

17. Rapoport JL, Giedd JN, Gogtay N (2012) Neurodevelopmental model of schizophrenia: update 2012. Mol Psychiatry 17:1228-1238. https://doi.org/10.1038/mp.2012.23.

18. American College of Obstetricians and Gynecologists (2015) Practice Bulletin No. 153: Nausea and vomiting of pregnancy. Obstet Gynecol 126:12-24.

https://doi.org/10.1097/AOG.0000000000001048

19. Boelig RC, Barton SJ, Saccone G, Kelly AJ, Edwards SJ, Berghella V (2016) Interventions for treating hyperemesis gravidarum. Cochrane Database Syst Rev 5: CD010607.

https://doi.org10.1080/14767058.2017.1342805.

20. Havnen GC, Truong MB, Do MH, Heitmann K, Holst L, Nordeng H (2019) Women's perspectives on the management and consequences of hyperemesis gravidarum - a descriptive interview study. Scand J Prim Health Care. 2019 37:30-40. https://doi.org/10.1080/02813432.2019.1569424

\section{Tables}

Table 1 Maternal characteristics in the study groups

\begin{tabular}{|c|c|c|c|c|c|}
\hline & & $\begin{array}{c}\text { Total } \\
(\mathrm{n}=386)\end{array}$ & $\begin{array}{c}\text { Hyperemesis gravidarum } \\
(\mathrm{n}=186)\end{array}$ & $\begin{array}{l}\text { Control } \\
(\mathrm{n}=200)\end{array}$ & $p$ value \\
\hline \multicolumn{6}{|l|}{ Maternal characteristics } \\
\hline Age (years), median (min/max) & & $\begin{array}{l}26(17 / \\
39)\end{array}$ & $26(18$ / 39) & $\begin{array}{c}26(17 / \\
36)\end{array}$ & $0.743^{1}$ \\
\hline \multicolumn{6}{|l|}{ Smoking, $n(\%)$} \\
\hline No & & $366(94.8)$ & $176(94.6)$ & $190(95.0)$ & \multirow[t]{2}{*}{$0.999^{2}$} \\
\hline Yes & & $20(5.2)$ & $10(5.4)$ & $10(5.0)$ & \\
\hline \multicolumn{6}{|l|}{ Parity } \\
\hline Nulliparous & & $220(57.0)$ & $106(57.0)$ & $114(57.0)$ & \multirow[t]{2}{*}{$0.999^{2}$} \\
\hline Multiparous & & $166(43.0)$ & $80(43.0)$ & $86(43.0)$ & \\
\hline \multirow{5}{*}{$\begin{array}{l}\text { Weight loss during pregnancy, } \\
\text { n (\%) }\end{array}$} & Yes & $170(44.0)$ & $170(91.4)^{*}$ & $0(0.0)$ & \multirow[t]{5}{*}{$<0.001^{3}$} \\
\hline & $<6.9 \mathrm{~kg}$ & $106(30.9)$ & $106(74.1)^{*}$ & $0(0.0)$ & \\
\hline & $\begin{array}{l}7-14.9 \\
\mathrm{~kg}\end{array}$ & $19(5.5)$ & $19(13.3)^{*}$ & $0(0.0)$ & \\
\hline & $\begin{array}{l}\geq 15.0 \\
\mathrm{~kg}\end{array}$ & $2(0.6)$ & $2(1.4)$ & $0(0.0)$ & \\
\hline & Missing & 43 & 43 & - & \\
\hline
\end{tabular}

\footnotetext{
${ }^{1}$ Mann Whitney U Test(Monte Carlo), ${ }^{2}$ Pearson Chi-Square Test (Exact), ${ }^{3}$ Fisher Freeman Halton Test(Monte Carlo)

${ }^{*} \mathrm{p}<0.001$ compared to control group
} 
Table 2 Delivery and fetal characteristics in the study groups

\begin{tabular}{|c|c|c|c|c|}
\hline & $\begin{array}{c}\text { Total } \\
(\mathrm{n}=386)\end{array}$ & $\begin{array}{c}\text { Hyperemesis } \\
\text { gravidarum }(\mathrm{n}=186)\end{array}$ & $\begin{array}{l}\text { Control } \\
(\mathrm{n}=200)\end{array}$ & $\begin{array}{c}\mathrm{p} \\
\text { value }\end{array}$ \\
\hline \multicolumn{5}{|l|}{ Delivery characteristics } \\
\hline $\begin{array}{l}\text { Gestational age (week), } \\
\text { median (Q1/Q3) }\end{array}$ & $\begin{array}{c}38.65(37.5 \\
/ 40)\end{array}$ & $38.6(37.6$ / 40) & $\begin{array}{l}39(37.5 / \\
40.05)\end{array}$ & $0.927^{1}$ \\
\hline \multicolumn{5}{|l|}{ Type of delivery, n(\%) } \\
\hline $\mathrm{C} / \mathrm{S}$ & $81(21.0)$ & $41(22.0)$ & $40(20.0)$ & \multirow[t]{2}{*}{$0.708^{2}$} \\
\hline Normal spontaneous delivery & 305 (79.0) & $145(78.0)$ & $160(80.0)$ & \\
\hline \multicolumn{5}{|l|}{ Fetal characteristics } \\
\hline \multicolumn{5}{|l|}{ Fetal gender, $n(\%)$} \\
\hline Female & $196(50.8)$ & $99(53.2)$ & $97(48.5)$ & \multirow[t]{2}{*}{$0.361^{2}$} \\
\hline Male & $190(49.2)$ & $87(46.8)$ & 103 (51.5) & \\
\hline $\begin{array}{l}\text { Fetal birthweight (gr), } \\
\text { median (Q1/Q3) }\end{array}$ & $\begin{array}{c}3265(2870 \\
/ 3640)\end{array}$ & $3250(2850$ / 3610) & $\begin{array}{l}3275(2915 \\
\quad / 3640)\end{array}$ & $0.698^{1}$ \\
\hline \multicolumn{5}{|l|}{ 5-min APGAR, n(\%) } \\
\hline$\geq 7$ & $376(97.4)$ & $181(97.3)$ & $195(97.5)$ & \multirow[t]{2}{*}{$0.999^{3}$} \\
\hline$<7$ & $10(2.6)$ & $5(2.7)$ & $5(2.5)$ & \\
\hline
\end{tabular}

${ }^{1}$ Mann Whitney U Test(Monte Carlo), ${ }^{2}$ Pearson Chi-Square Test (Exact), ${ }^{3}$ Fisher Exact Test(Exact)

Table 3 Adverse pregnancy outcomes in study groups 


\begin{tabular}{|c|c|c|c|c|}
\hline & $\begin{array}{c}\text { Total } \\
(\mathrm{n}=386)\end{array}$ & Hyperemesis gravidarum $(\mathrm{n}=186)$ & $\begin{array}{l}\text { Control } \\
(\mathrm{n}=200)\end{array}$ & $\mathrm{p}$ value \\
\hline \multicolumn{5}{|c|}{$\begin{array}{l}\text { Adverse pregnancy outcomes, } \mathrm{n}(\%) \\
\text { Preterm delivery }\end{array}$} \\
\hline No & $349(90.4)$ & $171(91.9)$ & $178(89.0)$ & \multirow[t]{2}{*}{0.388} \\
\hline Yes & $37(9.6)$ & $15(8.1)$ & $22(11.0)$ & \\
\hline \multicolumn{5}{|c|}{ Small for Gestational Age } \\
\hline No & $356(92.2)$ & $175(94.1)$ & $181(90.5)$ & \multirow[t]{2}{*}{0.253} \\
\hline Yes & $30(7.8)$ & $11(5.9)$ & $19(9.5)$ & \\
\hline \multicolumn{5}{|c|}{ Hypertensive disorder } \\
\hline No & $361(93.5)$ & $176(94.6)$ & $185(92.5)$ & \multirow[t]{2}{*}{0.417} \\
\hline Yes & $25(6.5)$ & $10(5.4)$ & $15(7.5)$ & \\
\hline \multicolumn{5}{|c|}{ Placental abruption } \\
\hline No & $383(99.2)$ & $184(98.9)$ & $199(99.5)$ & \multirow[t]{2}{*}{$\mathrm{N} / \mathrm{A}$} \\
\hline Yes & $3(0.8)$ & $2(1.1)$ & $1(0.5)$ & \\
\hline \multicolumn{5}{|c|}{ Stillbirth } \\
\hline No & $385(99.7)$ & $186(100.0)$ & 199 (99.5) & \multirow[t]{2}{*}{ N/A } \\
\hline Yes & $1(0.3)$ & $0(0.0)$ & $1(0.5)$ & \\
\hline \multicolumn{5}{|c|}{ Gestational diabetes } \\
\hline No & $374(96.9)$ & $179(96.2)$ & $195(97.5)$ & \multirow[t]{2}{*}{0.564} \\
\hline Yes & $12(3.1)$ & $7(3.8)$ & $5(2.5)$ & \\
\hline
\end{tabular}

Pearson Chi-Square Test (Exact) 